\section{Modificaciones introducidas a la Ley sobre Transparencia, Límite y Control del Gasto Electoral por la Ley № 20.053}

Davor Harasic*

\section{Introducción}

El Mensaje del proyecto que derivó en la dictación de la Ley № 20.053, que modifica la anterior sobre Transparencia, Límite y Control del Gasto Electoral, señala que se advierte la necesidad de modificar la normativa vigente, con el fin de optimizar y regular de manera más eficiente los mecanismos de financiamiento fiscal y privado, a la luz de la aplicación práctica por parte de los organismos estatales, candidatos y partidos políticos. "Desde el punto de vista de la eficiencia administrativa de la aplicación y no necesariamente de los criterios acerca del mérito de las normas, hay aspectos que requieren reformas urgentes", agregando el Mensaje que "se manifiestan algunos vacíos que es necesario solventar y otras omisiones que habían constituido una opción legislativa y que llegó la hora de revisar, como es el caso del financiamiento de las elecciones presidenciales".

El mismo Mensaje explica que la experiencia comparada indica que las normas electorales de esta naturaleza están sometidas a permanentes reformas, producto de la experiencia que arroja cada una de las elecciones. Chile no es la excepción, puesto que ya se han modificado tres veces las referidas a la materia. En concordancia con esto, el Mensaje asume que las reformas presentadas no son la última palabra, ya que "estas normas han generado y seguirán generando un conjunto de propuestas que tiendan a objetivos similares o eventualmente contrapuestos. No obstante, el propósito central no puede perderse de vista y el paso dado en el funcionamiento de la ley nos hace pensar que la decisión de adoptarlo fue positiva, pero perfeccionable y hacia allá irán dirigidos nuestros propósitos".

El conjunto de reformas que presenta el proyecto -hoy ley- tiene como eje central el perfeccionamiento de su transparencia, la facilitación de su efectividad, mejorando la aplicación de sus procedimientos de cobro y reembolso de gastos, así como la definición de sus omisiones.

Aclara el Mensaje que las modificaciones no vienen a cuestionar las ideas esenciales de la norma madre, esto es:

- pretender disminuir la influencia del dinero en las opciones de los ciudadanos, haciendo más austeros los procesos electorales, imponiendo límites de gastos;
* Abogado, Presidente de Chile Transparente, Capítulo Chileno de Transparencia Internacional y Secretario General de la Universidad Alberto Hurtado.

Este comentario, junto con el documento principal a que se refiere, están disponibles en www.anuariocdh.uchile.cl 
1 Walecki, Marcin, "Dinero político y corrupción", en Informe Global de la Corrupción 2004 de Transparencia Internacional, edición en español, Buenos Aires, 2004.

2 Ibid.

3 Ibíd.

4 Seguimos en la distinción a Marcin Walecki, op. cit.
- introducir formas básicas de financiamiento público como manera de garantizar un piso de igualdad de oportunidades de aquellos partidos políticos y candidatos independientes que aspiran a la dirección de los asuntos municipales, parlamentarios y ahora presidenciales;

- introducir mecanismos de transparencia que tiendan a precaver futuras colusiones de intereses sobre la base de dar conocimiento a la ciudadanía de los aportes y también de evitar la extorsión y el soborno;

- incorporar mecanismos de control que permitan que objetivos de esta naturaleza tengan plena eficacia y eficiencia.

\section{La política, la democracia, el dinero, la transparencia y la corrupción}

La importancia, en un sistema democrático, de la regulación del financiamiento político es de aceptación general en muchos países, incluido el nuestro.

El dinero es importante en la democracia porque mucha de su actividad política no podría tener lugar sin él, pero su mal uso en política genera problemas importantes, pues amenaza los principios democráticos de justicia equitativa y representación limpia'.

Los problemas del financiamiento político están en el núcleo del debate público sobre la corrupción política. El financiamiento político y la corrupción son nociones separadas; cuando sus valencias se superponen aparece la zona de corrupción política² ${ }^{2}$.

La corrupción política en el financiamiento político no suele ser algo claro. En general, el financiamiento político corrupto implica el manejo impropio o ilegal de operaciones financieras (con frecuencia por parte de un candidato o partido) en beneficio de un candidato individual, partido político o grupo de intereses ${ }^{3}$.

\section{a. Medidas para regular el financiamiento político}

Se debe distinguir el financiamiento político ilegal del financiamiento político irregular ${ }^{4}$. Es ilegal lo que la ley determine que es tal, o lo que es contrario a la ley. Por ejemplo, los aportes hechos por organismos públicos son ilegales en nuestro país, pues están prohibidos por la ley. El financiamiento político irregular, en cambio, surge de la brecha existente entre las disposiciones legales y la realidad de las prácticas. Puede suceder que algunos actos corruptos no sean ilegales y viceversa. El sistema irregular o informal del financiamiento político puede asociarse con aportes o donaciones que son legales, pero que provienen de fuentes cuestionables o se hacen a cambio de favores, todo ello no contra la ley, sino al margen de la ley. De modo tal, que las distintas medidas que se adopten en un país, a través de modificaciones legales, deberían tender a cerrar esta brecha, estableciendo reglas o mecanismos de control que limiten el margen para zonas "grises". 
Las principales medidas para controlar el dinero en la política, en orden de mayor a menor utilización en los países, son el financiamiento público, vetos y prohibiciones (principalmente a corporaciones, sindicatos y donantes del exterior), límites a los gastos, límites a las contribuciones y la divulgación absoluta (mecanismos de transparencia absoluta) ${ }^{5}$.

Transparencia Internacional entrega los siguientes estándares sobre financiamiento político y discrecionalidad ${ }^{6}$ :

1. eliminar la venta de influencias y los conflictos de intereses;

2. transparencia por medio de la difusión y la publicación;

3. efectividad en la aplicación y supervisión de las medidas de regulación;

4. diversidad de ingresos y límites al gasto;

5. equidad e integridad en el acceso a los medios de comunicación;

6. participación de la sociedad civil.

Vamos, pues, al análisis de tres de los principios que pretende perfeccionar la modificación legal:

\section{b. Límites de gastos}

La normativa sobre límites de gastos no sufre ninguna gran modificación con la nueva Ley № 20.053 .

Salvador Valdés explica que uno de los argumentos que justifica imponer límites al gasto electoral es evitar que la desigualdad económica relativa alcance niveles tales, que permita a los candidatos mejor financiados ahogar en publicidad a sus competidores ${ }^{7}$.

En Chile ya existen otros límites que dificultan a los candidatos mejor financiados obtener tal resultado. La Ley № 18.700 prohíbe a los canales de televisión abierta y de cable transmitir publicidad de candidaturas y partidos. También prohíbe a las radios y prensa escrita transmitir publicidad de candidaturas y partidos fuera del período electoral. Además, la ley otorga facultades a los alcaldes para retirar la publicidad callejera fuera del mismo período limitado (estas facultades se han ejercido y han tenido cierto efecto, pero están aún muy lejos de aplicarse plenamente). No es menos importante que Chile ofrece una franja electoral de televisión en las elecciones presidenciales y parlamentarias. Según Valdés, en su enfoque conceptual esta franja es exactamente opuesta a los límites al gasto total: para evitar que los candidatos mejor financiados ahoguen a sus competidores, opta por ayudar a los competidores peor financiados, en vez de gravar a los candidatos mejor financiados ${ }^{8}$.

En la misma línea se manifiesta Carlos Peña, quien sostiene que el establecimiento de límites parece presentar múltiples problemas desde el punto de vista de una correcta política pública en esta materia9: "La experiencia comparada muestra que la fiscalización de los límites globales al gasto es demasiado costosa si se quiere ser eficaz y es probable que
5 Ward, Gene, "El papel de la divulgación en el combate contra la corrupción en el financiamiento político", en Informe Global de la Corrupción 2004 de Transparencia Internacional, Buenos Aires, 2004.

6 Información extraída del sitio web de Transparencia Internacional www.transparency.org

7 Valdés, Salvador, "Financiamiento político: la estrategia y una ley buena", en Estudios Públicos, № 87, invierno 2002.

8 Ibíd.

9 Peña, Carlos, "Dinero y Política. Sobre las formas de financiamiento electoral", en Estudios Públicos, № 84, primavera 2001. 
${ }^{10}$ Walecki, op. cit.

11 Ibíd. los ricos tengan más incentivos y estén mejor dotados que los candidatos pobres para la evasión. Si esto es así, el establecimiento de límites podría acrecentar la desigualdad en vez de remediarla. Puede, además, lesionar bienes en extremo valiosos para una democracia. Baste señalar una regla como esa -para tener visos de ser eficiente- debiera ser capaz de detectar y limitar también el gasto de grupos que promueven temas claramente identificados con una candidatura. El límite al gasto obligaría -si la regla quiere evitar evasiones y no ser simple letra muerta- a sacrificar la densidad del debate y controlar la promoción de ideas distinguiendo en el límite- entre ideas políticas y no políticas. Los límites al gasto podrían, de esta manera, sacrificar el ideal deliberativo que, hemos visto, anima a la democracia. De otro lado, la Comisión del CEP dispuso de alguna evidencia empírica que mostraba que la productividad publicitaria de un candidato titular es menor que la de un candidato desafiante. Los desafiantes, en otras palabras, pierden más que los titulares al existir un límite global. Esto permite pensar que un límite al gasto deteriora la circulación de las elites y disminuye la competencia política. Los titulares de los cargos de elección popular -que poseen ya ventajas en razón del cargo que poseen- podrían, por esta vía, perjudicar el éxito de los aspirantes".

Por cierto que la limitación al gasto tiene fundamento en los excesos a que su no existencia podría acarrear.

\section{Financiamiento público}

El financiamiento público es otro principio no alterado por las recientes modificaciones, aunque se regulan ciertos aspectos para su transparencia.

Esta forma de financiamiento público directo pretende proveer un piso de igualdad entre los candidatos mejor y peor financiados, y evitar a los partidos la incesante presión por conseguir fondos. El financiamiento público es muy común en Europa Occidental, Europa Central y del Este y en América Latina ${ }^{10}$.

Pero como demuestran los escándalos a lo largo del mundo, incluso un fuerte financiamiento público no es suficiente para eliminar otras formas de financiamiento político vinculado con la corrupción, como el enriquecimiento personal, los gastos ilegales o la compra de votos ${ }^{11}$.

\section{d. Mecanismos de transparencia (divulgación)}

Las modificaciones más relevantes que introduce la Ley № 20.053, si bien se refieren principalmente a aspectos más bien operacionales, dicen relación con perfeccionar la transparencia en el financiamiento político. Del mismo modo los mecanismos de control que se establecen miran, en general, al mismo objetivo.

Así, por ejemplo, se establece que la cuenta para la recepción de transferencias de aportes reservados deben ser de titularidad del candidato, para que no haya distorsiones (los aportes ya no son asignados por un administrador que puede serlo de varios candidatos, y quien podría 
asignar los aportes con criterios distintos a la asignación de los donantes); se establece que los candidatos pueden recurrir al sistema financiero, pero sólo con instituciones formales, registradas en la Superintendencia de Bancos e Instituciones Financieras, acreditándose el fin y el uso electoral del crédito; también se establece un mecanismo de control para los límites relacionados con los aportes de personas jurídicas que reciben subvenciones o aportes del Estado, así como aquellas que participan en licitaciones con sus organismos, en el sentido de que para estos efectos, estas personas jurídicas deberán estar inscritas en el Registro de Contratistas de la Ley de Bases sobre Contratos Administrativos de Suministro y Prestación de Servicios (Ley № 19.886). Se explicita que los aportes públicos son la regla general y que cualquier aporte puede tener tal carácter, aun cumpliéndose las condiciones para que sea reservado. En cuanto a la contabilidad de los partidos políticos, se explicita que el registro del balance del gasto electoral de los partidos o candidatos debe incluir tanto gastos como ingresos y no sólo los primeros.

Sin embargo, no se modifica en lo sustancial el sistema ya existente que contempla aportes reservados y públicos.

Lo que se puede denominar como transparencia o divulgación absoluta, esto es, que cualquier ciudadano pueda conocer cómo y de dónde obtiene el financiamiento un partido o candidato -con la correlativa obligación de hacerlo público- encuentra firmes adherentes en otros países. Transparencia Internacional sostiene que "es fundamental la revelación de los movimientos de dinero; el financiamiento político debe estar registrado y que resulte claro. No se justifica nada que no sea la absoluta transparencia sobre los fondos de la política. Aunque hay consenso en esto entre políticos y activistas, la realidad es muy diferente, pues hay numerosas formas de limitar la difusión"12.

La difusión de las cifras del financiamiento político trae consigo varios beneficios: genera la capacidad de seguir el dinero (mejor contabilidad); actúa como medida preventiva (no sólo represiva); es la medida menos polémica, la más susceptible de apoyo político, y crea confianza en el proceso democrático $^{13}$.

Dos tendencias con diferentes lecturas acerca de la conveniencia de la divulgación son dignas de mención ${ }^{14}$ :

- Una considera la equivalencia moral entre el secreto del voto y el secreto de una donación (Suecia, Finlandia y Suiza, donde no existen exigencias de divulgación).

- Otra se preocupa por el hostigamiento que pueden sufrir los aportantes cuando se sabe que han apoyado a "otro" candidato o partido (como ha sucedido en Ucrania y Egipto).

En contraposición a un sistema de divulgación, o transparencia y/o publicidad total, en Chile deliberadamente se ha optado por un régimen de donaciones indirectas y confidenciales que coexiste con un sistema de donaciones directas y públicas.
12 Hodess, Robin, Informe Global de la Corrupción 2004 de Transparencia Internacional (Introducción), edición en español, Buenos Aires, 2004.

13 Ward, op. cit.

14 Ibíd. 
15 Peña, op. cit.

16 Fuentes, Claudio: Lecciones del gasto electoral, diario La Tercera, 23 de enero de 2006.
Carlos Peña explica que la publicidad total puede facilitar la extorsión y la corrupción: si un candidato amenaza con represalias para obtener un aporte (extorsión), o un donante ofrece dinero a cambio de favores en el sistema político (corrupción), en ambos casos, la publicidad total permite que se verifiquen los pagos y se puedan hacer exigibles las promesas. $\mathrm{Si}$, en cambio, se genera incertidumbre, se desincentivan esos tipos de intercambios: el extorsionador no tendrá cómo verificar si su amenaza fue exitosa y quien corrompe no tendrá cómo hacer valer su pago ante el candidato. El resultado es que el actor político recupera -gracias a la incertidumbre- su autonomía frente al donante o se ve privado de la posibilidad eficaz de extorsionarlo. La publicidad total, por el contrario, puede perjudicar, en vez de favorecer, la autonomía del político ${ }^{15}$.

La transparencia total -sostiene Peña-también podría facilitar represalias o castigos hacia el candidato o hacia los donantes. Por ejemplo, puede suceder que se amenace con dañar en el futuro a personas que no donen dinero a un determinado candidato (o donen a sus rivales). En un sistema de transparencia total, inevitablemente se conocen las preferencias de los donantes: esto podría inhibir a una persona de donar a un candidato que su grupo social rechaza. De esta forma, la publicidad total tiende a disminuir la competencia política. Incluso si alguien solamente desea mantener en secreto su preferencia política, la pérdida de privacidad podría desalentar el financiamiento privado.

Nos parece que las aprensiones de Peña y Valdés pueden solucionarse por vía distinta a la opacidad. Estimamos que no hay razón para que la ciudadanía no pueda ejercer el voto informadamente, sabiendo con exactitud las fuentes de financiamiento de cada candidatura. El sistema actual es engorroso y poco transparente; sólo tres meses después de la elección se pueden conocer los montos declarados por cada candidatura $y$, transcurrido dicho período, tampoco se conoce la totalidad de los fondos ni se sabe si lo declarado se acerca a lo gastado ${ }^{16}$. 